\title{
НОВЫЕ ИССЛЕДОВАНИЯ ПАМЯТНИКА САЙМАЛЫ-ТАШ (КЫРГЫЗСТАН, ФЕРГАНСКИЙ ХРЕБЕТ)
}

\section{(C) 2021 г. А.Т. Сулайманова}

В 2016 году Министерством культуры, информации и туризма Кыргызской Республики была организована и финансирована программа по исследованию и документированию крупного памятника наскального искусства Саймалы-Таш. Программа «Первичное археологическое и историко-архитектурное исследование Государственного природного парка «Саймалуу-Таш» и его прилегающих территорий с частичным документированием объектов историко-культурного наследия», реализовывалась в ходе двух сезонов 2016-2017 гг. Работы на памятнике проводились в рамках поставленных задач проекта и итоги были предоставлены Министерству культуры КР в виде отчета, был издан первый альбом о памятнике наскального искусства Саймалы-Таш. Благодаря этому проекту, впервые удалось сделать детальную и обширную топографию памятника, подсчитать количество камней с рисунками с применением тахеометра и точные местонахождения каждого наскального рисунка, выявить объекты другой категории в районе основных скоплений петроглифов и внести их местоположение в карту. Разведочные исследования проводились в широком масштабе.

Ключевые слова: археология, Кыргызстан, Ферганский хребет, Саймалы-Таш I и II, петроглифы, документирование, топосъемка, разведка, курганы, мониторинг, буферная зона, природный парк.

\section{NEW STUDIES OF THE SAIMALY-TASH MONUMENT (KYRGYZSTAN, FERGHANA RIDGE)}

\section{A.T. Sulaimanova}

In 2016, the Ministry of Culture, Information and Tourism of the Kyrgyz Republic organized and funded a program for the study and documentation of a large monument of rock art Saimaly-Tash. The program "Primary archaeological and historical-architectural study of the Saimaluu-Tash State Natural Park and its adjacent territories with partial documentation of historical and cultural heritage objects" was implemented during two seasons of $2016-2017$. The works on the monument were carried out within the framework of the project objectives and the results were provided to the Ministry of Culture of the Kyrgyz Republic in the form of a report, the first album about the Saimaly-Tash rock art monument was published. Thanks to this project, for the first time it was possible to make a detailed and extensive topography of the monument, count the number of stones with drawings using a total station and the exact locations of each rock art, identify objects of a different category in the area of the main clusters of petroglyphs and enter their location in the map. Exploration work was carried out on a large scale.

Keywords: archaeology, Kyrgyzstan, Ferfgana Ridge, Saimaly-Tash I and II, petroglyphs, documentation, topography, exploration, mounds, monitoring, buffer zone, nature park.

Памятник наскального искусства СаймалыТаш находится на северо-восточных склонах Ферганского хребта в Тянь-Шане. Этот горный хребет тянется с юго-востока на северо-запад, отделяя Ферганскую долину от Внутреннего Тянь-Шаня. Хребет имеет асимметричное строение с длинными и пологими юго-западными склонами и крутыми северо-восточными. К юго-западным отрогам Ферганского хребта относятся хребты БабашАта, Сууган-Таш, Сёрюн-Дёбё и другие. Югозападные склоны хребта расчленены крупными, протяженными ущельями рек Кулун, Кара-Кульджа, Джазы и Кара-Ункур. Северовосточный склон рассекается относительно короткими, узкими и труднопроходимыми ущельями притоков основных рек - Арпа, Пчан, Кок-Арт, Кокилим-Бель. Среди множества завальных озёр, относящихся к хребту, наиболее крупные - Кулун и Кара-Суу.

На склонах хребта организованы особо охраняемые природные территории. Одной из них является Государственный природный парк «Саймалуу-Таш», к которому относится урочище Саймалы-Таш с наскальными рисунками.

Урочище Саймалы-Таш расположено на северо-восточной стороне Ферганского хребта в верховьях одноименного ручья (рис. 1). Вдоль ручья, от его впадения в р. Кок-Арт до самого водораздела, проходит тропа с выходом на противоположный склон хребта. Это 


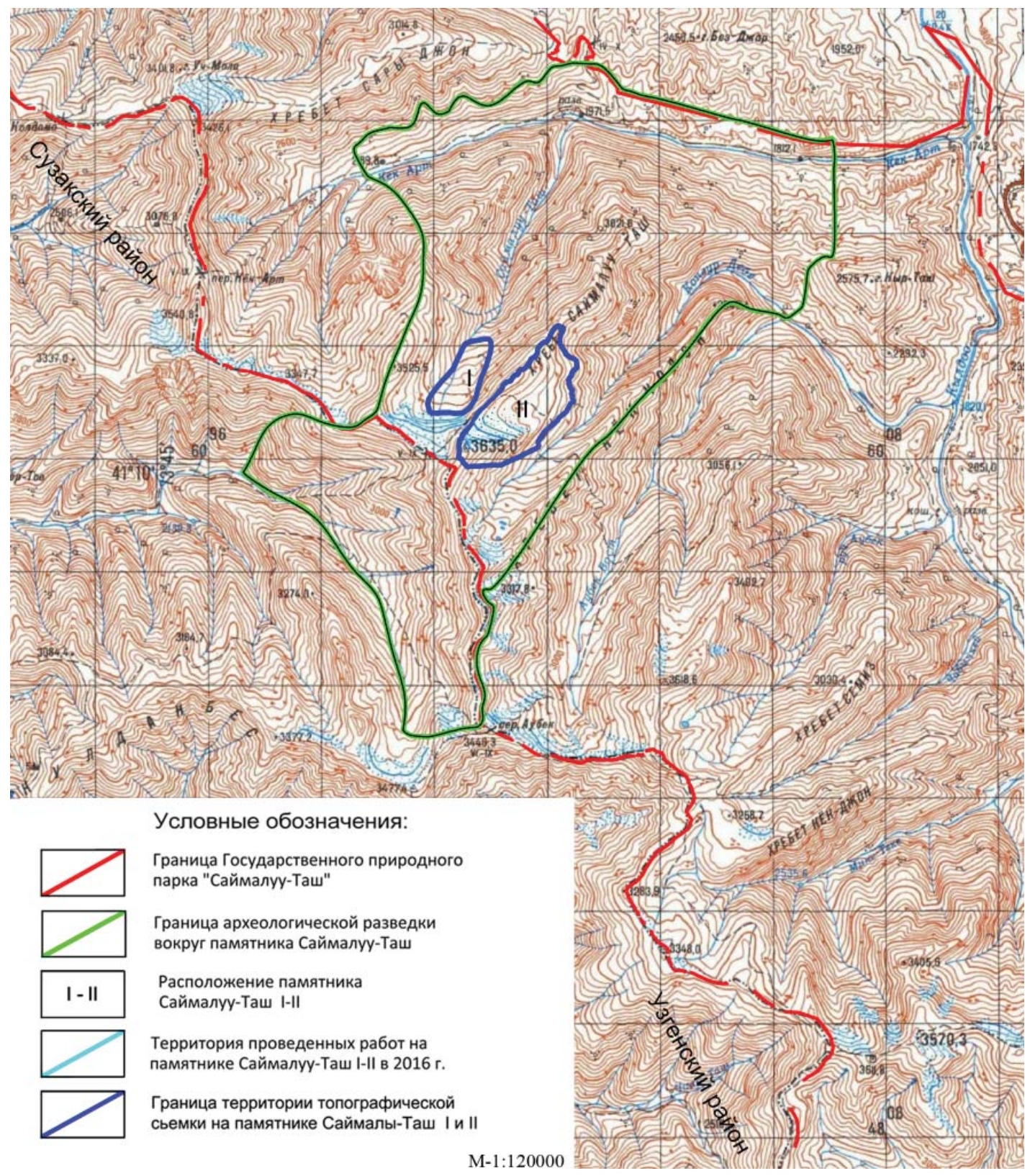

Рис. 1. Местонахождение памятника Саймалы-Таш I и II с обозначением границ топосъемки 2016-2017 гг.

Fig. 1. The location of the monument of Saimaly-Tash I and II with the designation of the boundaries of the 2016-2017 survey

«безымянный» перевал, расположенный на равном расстоянии между двумя перевалами - Кок-Арт с северо-запада и Аубек с юговостока.

Изучение памятника наскального искусства ведется уже более ста лет, с тех пор как в кругах Российского научного сообщества появились первые сообщения о наскальных рисунках Саймалы-Таш (Хлудов, 1902, с. 40-43; Пославский, 1903, с. 75-83). Исследование петроглифов Саймалы-Таша неоднократно возобновлялось в советский период: результаты этих работ освещались в трудах Б.М. Зимы (1945), А.Н. Бернштама (1997), Г.А. Помаскиной $(1969,1975)$, Г.А. Голенду- хина (1971), Н.А. Подольского (1978), Я.А. Шера (1982), Л.Дж. Джусупакматова (2013), К.И. Ташбаевой (1990), А.И. Мартынова, А.Н. Марьяшева, А.К. Абатекова (1992), А.Е. Рогожинского (2008) и др. Ими же внесен значительный вклад в изучение памятника, разработку вопросов о времени его возникновения, типологии и датировке отдельных групп рисунков, интерпретации семантики петроглифов. Применялись разные методы документирования памятника: фотофиксация, изготовление контактных копий рисунков на разных материалах (калька, полиэтиленовая пленка, микалентная бумага), снятие топоплана памятника, определение количества 
камней с изображениями и самих рисунков (Бернштам, 1997, с. 388-407; Помаскина, 1969, с. 450-452; Ташбаева, 2004, с. 93-106). Типологическая характеристика петроглифов Саймалы-Таша впервые была предоставлена А.Н. Бернштамом, и вопросы происхождения, культурной атрибуции древних петроглифов памятника остаются в целом в рамках предложенной им схемы (Бернштам, 1997, с. 394-406).

В 2001-2012 гг. в рамках экспедиции Института истории Национальной академии наук Кыргызской Республики (руководитель К.И. Ташбаева) с региональным представительством ЮНЕСКО в Алматы и Центром научных исследований Франции (руководитель А.-П. Франкфор) проводились топографическая съемка расположения и учет петроглифов Саймалы-Таш I и II. C плоскостей с изображениями выборочно были сняты силиконовые негативы, с которых сделаны муляжные копии, производились раскопки курганов на Саймалы-Таш II. К настоящему времени большинство исследователей придерживаются датировки петроглифов Саймалы-Таша в интервале от второй половины III - начала II тыс. до н. э. до Х в. н. э. (Шер, Голендухин, 1982, c. 23-24; Рогожинский, 2008, с. 87-90; Ташбаева, 2004, с. 101; 2019, с. 213-214).

В рамках государственного проекта Министерством культуры, информации и туризма КР выполнялись топографические съемки территории Саймалы-Таш I и II, инструментальная инвентаризация петроглифов; фотофиксация, мониторинг состояния плоскостей с изображениями, аэрофотосъемка с дроном, разведки на прилегающих зонах памятника и на восточной части самого государственного природного парка «СаймалууТаш». По завершении работ первого сезона проекта издан альбом о петроглифах Саймалы-Таш I и II (Сулайманова и др., 2016, c. 304).

Документирование памятника проводилось на Саймалы-Таш I и Саймалы-Таш II (разделение и наименование памятника по А.Н. Бернштаму). Они расположены в двух отдельных соседствующих участках, географически четко разграничивающихся водоразделом Саймалы-Таш - северо-восточным отрогом Ферганского хребта. Саймалы-Таш I занимает донную часть одноименной долины межгорных водоразделов с ручьем СаймалыТаш (другое наименование Согот). СаймалыТаш II занимает восточный склон хребта Саймалы-Таш, где отрог образован сходом ледника (рис. 2).

При инвентаризации петроглифов Саймалы-Таш I для удобства работы долина условно разделена на восточную и западную части. Границей намечен ручей СаймалыТаш. Основное местонахождение наскальных рисунков находилось в восточной части долины, и, соответственно, документирование проводилось на этом секторе памятника (западная часть запланирована на последующие годы работ).

Учет петроглифов выполнен с тахеометром в системе WGS-84. Вначале выявлен и индексирован каждый камень с рисунками, следом каждая плоскость его с изобразительными поверхностями. Затем производились фотофиксация и измерение тахеометром камней с рисунками. Все эти материалы систематизированы и сведены в единую таблицу базы данных инвентаризации с гиперссылкой на фотоматериал и координаты местоположений петроглифов.

Топографическая съемка территории Саймалы-Таш I производилась в восточной части одноименного урочища и охватила площадь около 80,0 га. Предварительная маркировка границ съемки определялась на месте памятника с учетом участков, где зафиксировались единичные петроглифы. Территория памятника Саймалы-Таш II, в сравнении с Саймалы-Таш I, значительно меньше. Поэтому здесь удалось произвести учет и топосьемку по всей территории распространения петроглифов (рис. 3). При этом площадь съемки составляла 235 га. По данным съемки составлен топографический план СаймалыТаш I и II в разных масштабах с обозначением местоположения индексированных петроглифов и других выявленных объектов истории и культуры. Таким образом, выявились предварительные очертания границ распространения петроглифов Саймалы-Таша.

По итогам учета петроглифов, на СаймалыТаш I насчитано 5486 единиц камней с рисунками, а на Саймалы-Таш II - 4582 единиц. Отдельный учет количества самих наскальных изображений (а также плоскостей камней), который является важным для документи- 

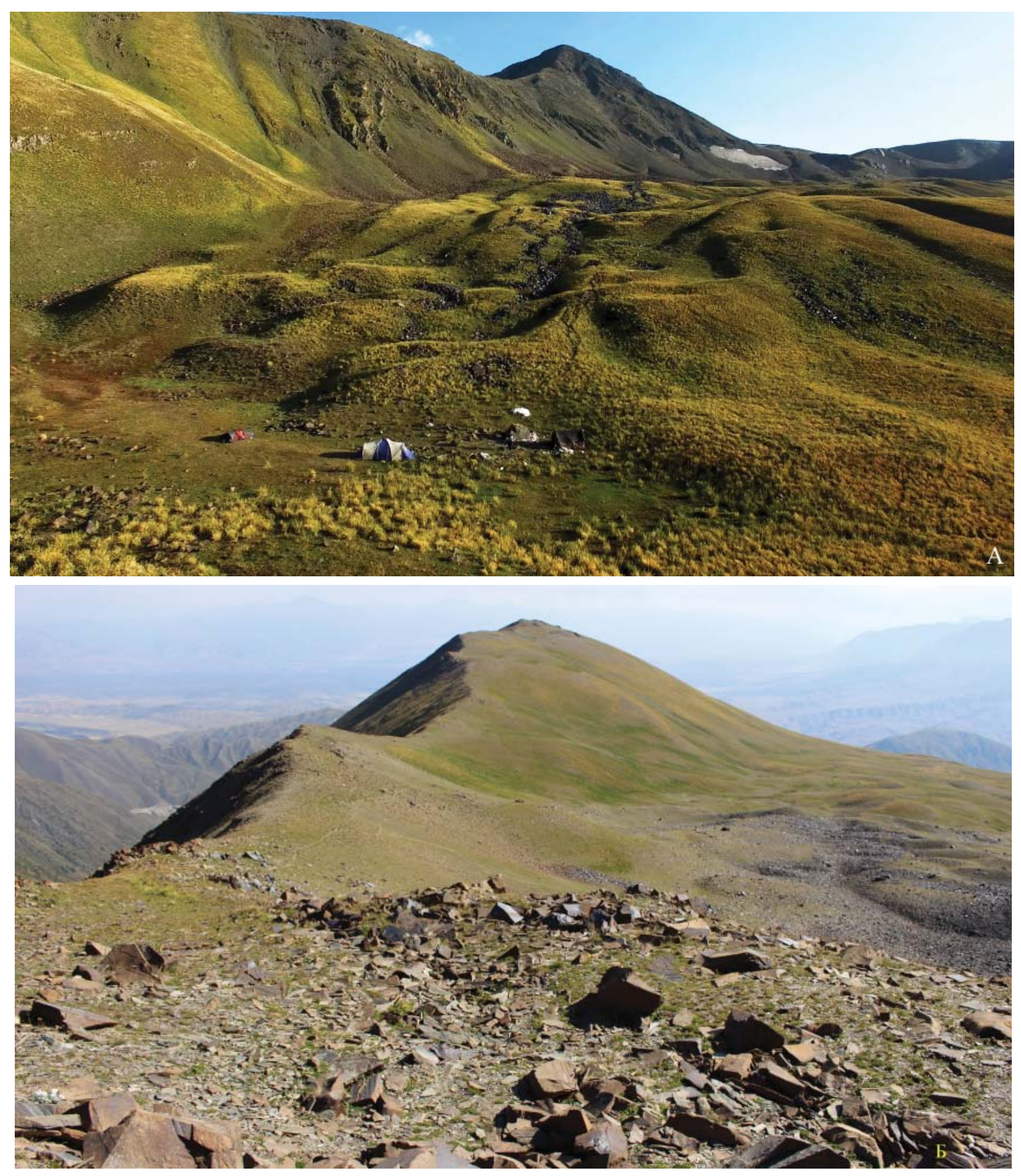

Рис. 2. А - общий вид памятника Саймалы-Таш I с северо-востока. Восточная часть одноименной долины с основным скоплением петроглифов; Б - вид восточного склона водораздела Саймалы-Таш, где расположен памятник Саймалы-Таш II

Fig. 2. A - general view of the monument of Saimaly-Tash I from the northeast. The eastern part of the valley of the same name with the main cluster of petroglyphs; Б - a view of the eastern slope of the Saimaly-Tash watershed, where the monument of Saimaly-Tash II is located

рования памятника, на месте не проводился. В настоящее время материалы учета петроглифов Саймалы-Таша являются наиболее точными. Поскольку предстоит в будущем еще документирование западной части урочища, количество учтенных петроглифов однознач- но будет увеличиваться. Ранее предсказанные подсчеты количества петроглифов были предположениями. А.Н. Бернштам писал, что в обоих местонахождениях наскальных изображений Саймалы-Таша им проведен среднестатистический подсчет (свыше 100 тыс.) 


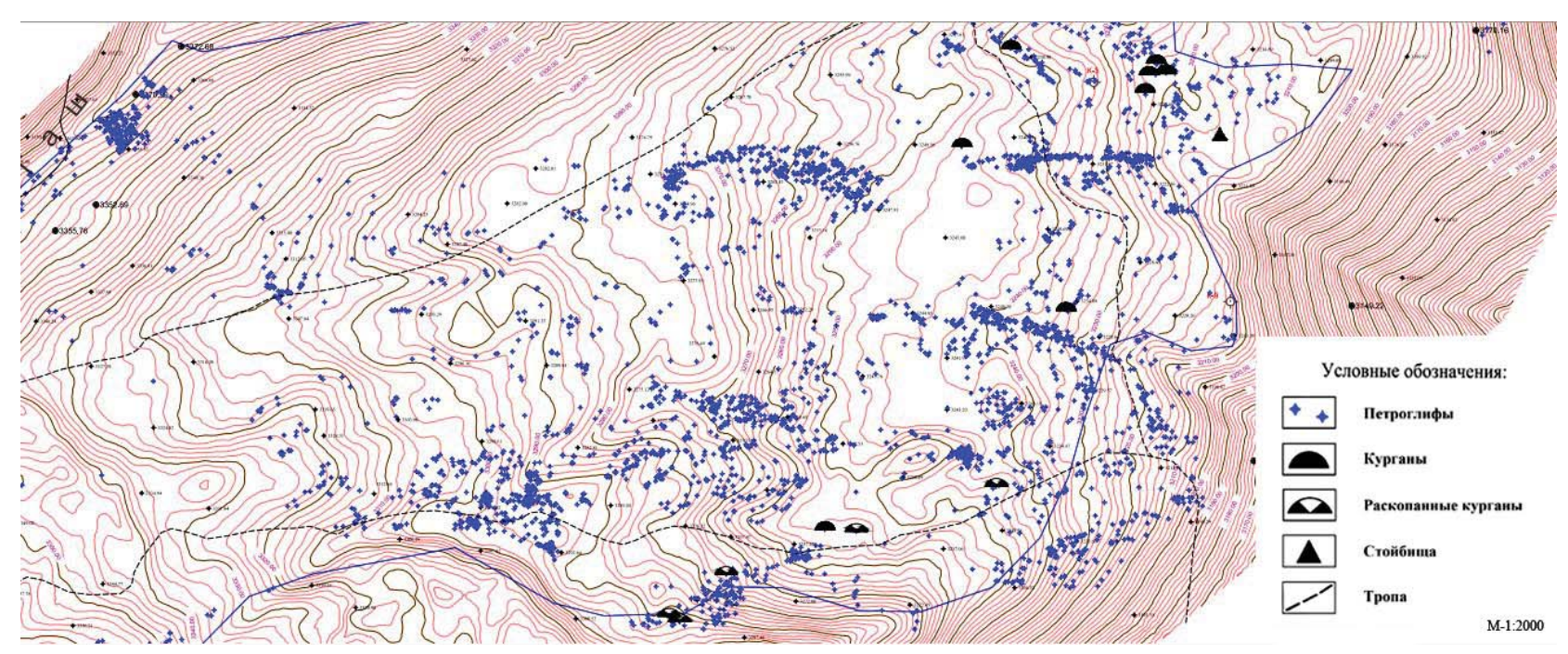

Рис. 3. Фрагмент топографического плана Саймалы-Таш II с местонахождением петроглифов и курганов

Fig. 3. A fragment of the topographic plan of Saimala-Tash II with the location of petroglyphs and mounds

(Бернштам, 1997, с. 393). Г.А. Помаскиной (Агафоновой) проведен целенаправленный учет самих изображений Саймалы-Таш I, и на площади 10 га насчитали 6020 единиц рисунков $^{1}$. К.И. Ташбаева упоминает наличие около 10 тыс. камней с рисунками в Саймалы-Таш I. Также она пишет, что на каждом камне имеется от одного до нескольких выбитых рисунков, иногда десятки, до 50-100 изображений на одном камне (Ташбаева, 2004, с. 97).

Также в рамках данной работы выполнено предварительное геоморфологическое исследование долины р. Саймалы-Таш сотрудником института геологии им. М.М. Адышева НАН КР В.П. Саньковой. Ею проведено исследование общей характеристики геоморфологических условий на основе анализа уже имеющихся карт, литературных данных, материалов, полученных при дешифрировании (интерпретации) аэрофотосъемки и космических снимков (разработка детальной геоморфологической карты долины р. Саймалы-Таш запланирована на дальнейших этапах полевых работ), и образцов камней, привезенных с урочища Саймалы-Таш. Благодаря этому были получены сведения о том, что в геологическом строении долины р. Саймалы-Таш и окружающих хребтов принимают участие среднепалеозойские и верхнепалеозойские осадочные породы, в основном глинистые сланцы, алевролиты, песчаники, известняки. Встречаются и гравелиты, конгломераты. До этого времени в сведениях о породе камней с наскальными изображениями упоминался только базальт.
Благодаря трудам ранних исследователей памятника Саймалы-Таш известно, что в стиле и технике исполнения наскальных изображений имеется ряд характерных особенностей. В частности, большое количество изображений геометрического стиля и применение комбинированных приемов (мелкие или грубые выбивки, сглаживание следов выбивки, оконтуривание края силуэтных персонаж гравировкой) в выполнении одного изображения. Поэтому рисунки, выполненные комбинированной техникой, документированы детально фотофиксацией и измерением технических данных рисунков.

Среди петроглифов Саймалы-Таша встречаются рисунки, нанесенные как на плоскостях, покрытых однотонным «пустынным загаром», так и на камнях со слабой патиной. Такие субстраты с рисунками, которые длительное время находились вне солнечного воздействия и открытого воздуха, могут показаться «свежими», но в то же время стиль исполнения рисунков имеет сходство с изображениями на камнях с густым загаром.

Наскальные рисунки (рис. 4-5) можно встретить практически по всему урочищу Саймалы-Таш - на поверхностях едва выступающих из-под земли камней или лежащих просто на поверхности. Бывает, что, наоборот, встречаются камни с ровной плоскостью, покрытой интенсивным загаром, удобной для нанесения рисунков, но без изображений или каких-либо следов выбивки.

При общем обзоре в качестве основной идеи в содержании наскальных изображений 


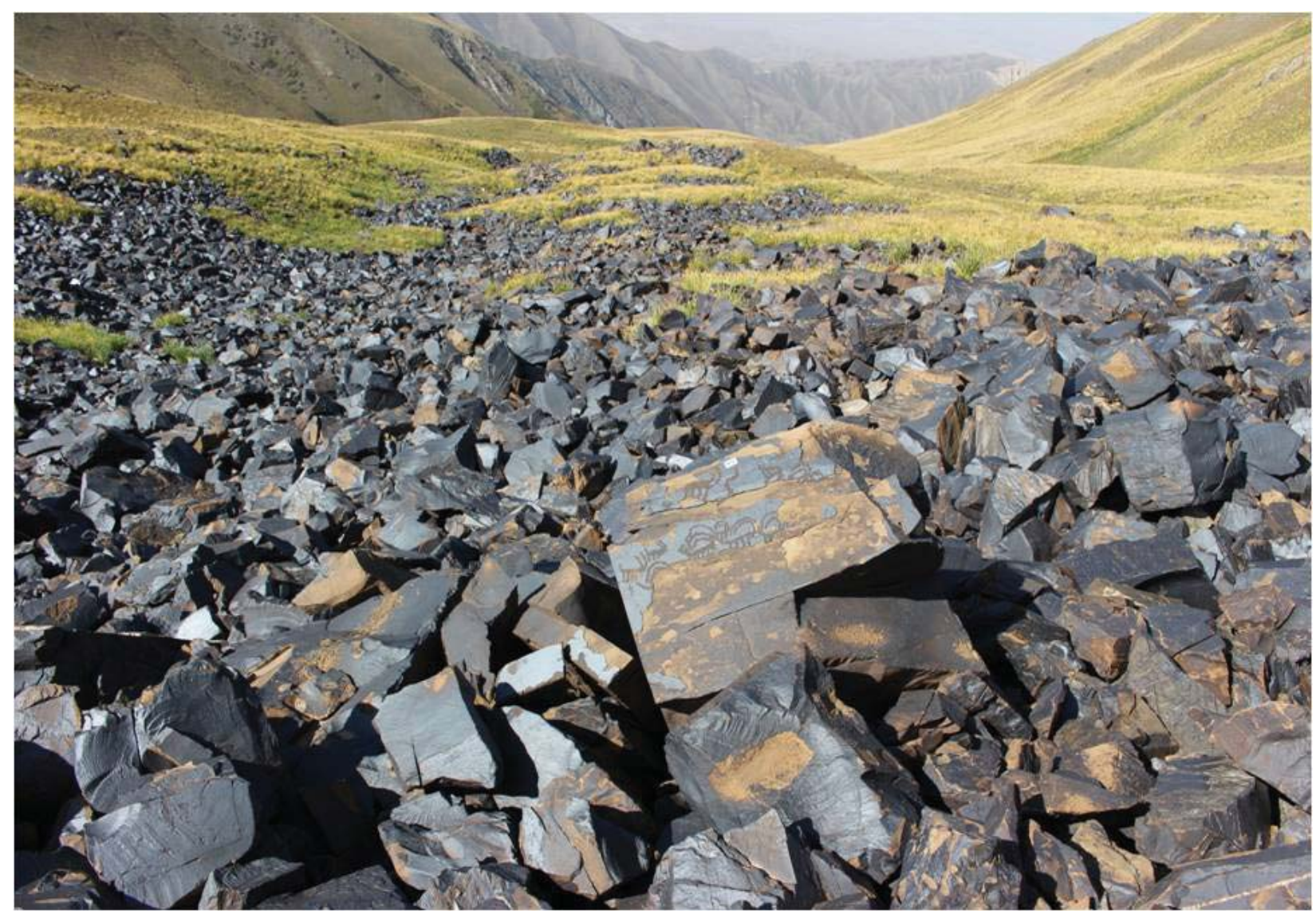

Рис. 4. Каменные обвалы (морена) Саймалы Таша I. Вид с юго-запада

Fig. 4. Rock falls (moraine) of Saimala Tasha I. View from the southwest

выделяются сюжеты рисунков, представляющие «повседневный быт» древнего общества и их «восприятие» окружающей среды, «мировоззрение» и «сакральную» сторону жизни. Создателями рисунков Саймалы-Таша вряд ли ставилась задача передать какуюнибудь информацию грядущим поколениям, о важном событии общества того времени и т. д. Однако эти петроглифы доносят до нас представление о «мирной повседневной» жизни людей из далеких ушедших эпох.

Если рассматривать с точки зрения эстетики и практичности, выбор местоположения камня и его плоскостей зависел от удобства расположения мастера в процессе нанесения рисунков. Но встречаются рисунки и на неудобных участках поверхности. Поэтому для осуществления замысла художника подходила, видимо, любая поверхность камня по его выбору. Поверхность некоторых камней была использована так, что на плоскости не оставалось свободного места, будто древний художник пытался отразить на «каменном полотне» все моменты своей жизни. Сюжеты такого рода также являются характерными в наскальных рисунках Саймалы-Таша.
Замечены и рисунки, нанесенные на «неудобных» участках скальных обломков, когда рисунки наносились на узких поверхностях между гранями, при этом более широкая плоскость камня не использовалась. Иногда рисунки выбивались на невидимой для подходящего зрителя стороне камня. Такое решение, возможно, является намеренным желанием древнего художника отобразить свое представление, олицетворяя конфигурацию камня с рельефом местного ландшафта и т. п.

Для петроглифов Саймалы-Таша характерны небольшие по величине рисунки. Размеры фигур варьируются от 9-10 до 25-30 см, нередко встречаются и миниатюрные изображения с тщательным исполнением деталей, достигающие 5-6 см. В целом наскальные изображения по величине можно охарактеризовать как средние и мелкие. Редко встречаются фигуры сравнительно крупные. Так, на Саймалы-Таш II зафиксированы изображения горного козла высотой $40 \mathrm{~cm}$, длиной $60 \mathrm{~cm}$; другой пример - «солярный» знак размером $32 \times 39$ см, а с «ножкой» -50 см.

Классификация наскальных рисунков Саймалы-Таша нами не проводилась, но 
дополнить репертуар наскальных рисунков можно некоторыми данными. Как известно, в репертуаре Саймалы-Таша имеются изображения антропоморфных и зооморфных персонажей и геометризованные рисунки. Встречаются также непонятные рисунки, неопределенные, незавершенные изображения и "эскизы рисунков".

Среди ранее неупоминаемых видов наскальных рисунков можно отметить изображения птиц, выполненные в разных стилях, и "непознаваемые силуэты" персонажей, знакисимволы, тамги (рис. 6).

Среди изображений птиц две схожие друг с другом силуэтные фигурки, нанесенные на одной плоскости камня, напоминают подвид страуса (например, казуар, эму или нанду). Также другое изображение птиц с повернутой назад головой, представляющее семейство орлиных, зафиксировано в трех разных участках памятника. Такое стилизованное изображение птицы с большими глазами и согнутым клювом, выполненное в скифском зверином стиле, широко распространено по всей Евразии как в наскальном искусстве, так и среди предметов торевтики. Третье изображение птицы выполнено в полете, с расправленными крыльями и вытянутой вперед головой, узким, но удлиненным хвостом. Голова птицы с детализированным клювом, повернута направо.

Также среди петроглифов Саймалы-Таша найдено несколько коротких надписей, выполненных арабской каллиграфией. Одна из них сопровождалась указанием даты 1904 г. Вероятнее всего, эти письмена были гравированы в XIX - начале XX вв.

Отметим и некоторые сведения, относящиеся к технике исполнения. Как известно, рисунки исполнены посредством разнообразной техники - выбивки, гравировки, протирки, выцарапывания и комбинированные. Наскальные рисунки нанесены в основном техникой точечной выбивки (грубой и мелкой), а рисунки, исполненные техникой гравировки, редки. Техника прошлифовки обычно применялась после нанесения силуэта фигур и обрабатывала шершавые поверхности следов от выбоины инструмента. На некоторых участках четко видны выравнивающие следы линии выреза по контуру рисунков. Прослеживается и сгла- живание следов скола от инструмента, и этим придавался завершенный вид рисункам.

В исполнении рисунков широко применялась техника комбинирования нескольких приемов нанесения. Можно увидеть «эскизы», нанесенные разрисовками, а также следы прерывающихся линий, которые чаще всего являются попыткой передачи контура задуманного образа (незавершенного). В то же время можно встретить и различить почерк художника, выполнившего рисунки на нескольких камнях. Например, на одном и том же небольшом участке, недалеко друг от друга находятся три почти одинаковых изображения одного из подвидов благородного оленя, отличающихся друг от друга лишь количеством роговых отростков.

Интересна техника гравировки, характеризуемая глубоким треугольным сечением и гладкими сторонами, как будто вырезана поверхность мягкого камня. На самом деле, по имеющимся геологическим данным, представленным В.П. Саньковой (Институт геологии НАН КР), долину р. Саймалы-Таш и окружающие хребты слагают средне- и верхнепалеозойские осадочные породы. Они представлены в различной степени метаморфизованными, часто окремненными, преимущественно темно-серого (до черного) цвета, местами с пёстрой окраской, алевролитами, песчаниками, глинистыми сланцами, иногда известняками, гравелитами и конгломератами. И глинистый сланец, и песчаник легко поддаются обработке и не имеют столь твердой структуры как базальт (А.Н. Бернштам определил камни как базальт). В статьях о памятнике Саймалы-Таш порода субстратов с рисунками отмечалась базальтом (А.Н. Бернштам, К.И. Ташбаева и др.).

На памятнике Саймалы-Таш много изображений, поднобновленных полностью или частично. Некоторые из них дорисовывали (внесены свои версии поправок), изменяя первоначальный облик рисунков, а иногда детализировали, добавляя рисункам уши, рога, хвосты и т. д. На некоторых плоскостях имеются сюжеты разного контекста, которые стилистически и по технике исполнения отличаются друг от друга. Рисунки выбиты рядом с ранее нанесенными рисунками (как дополнение к сюжету?), и вся поверхность каменного «полотна» покрывалась разновременны- 

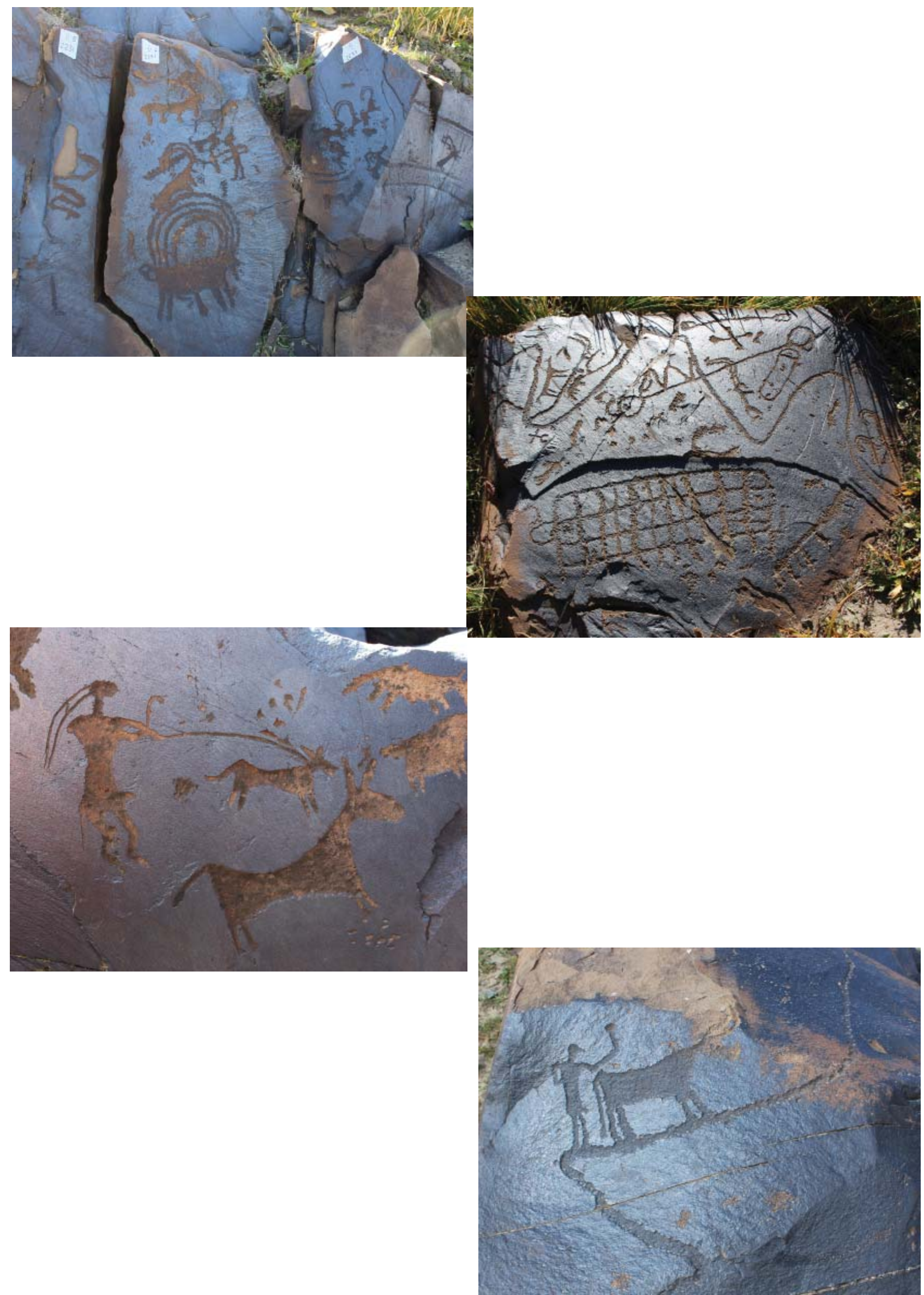

Рис. 5. Петроглифы памятников Саймалы-Таш I и II

Fig. 5. Petroglyphs of the monuments of Saimala-Tash I and II 

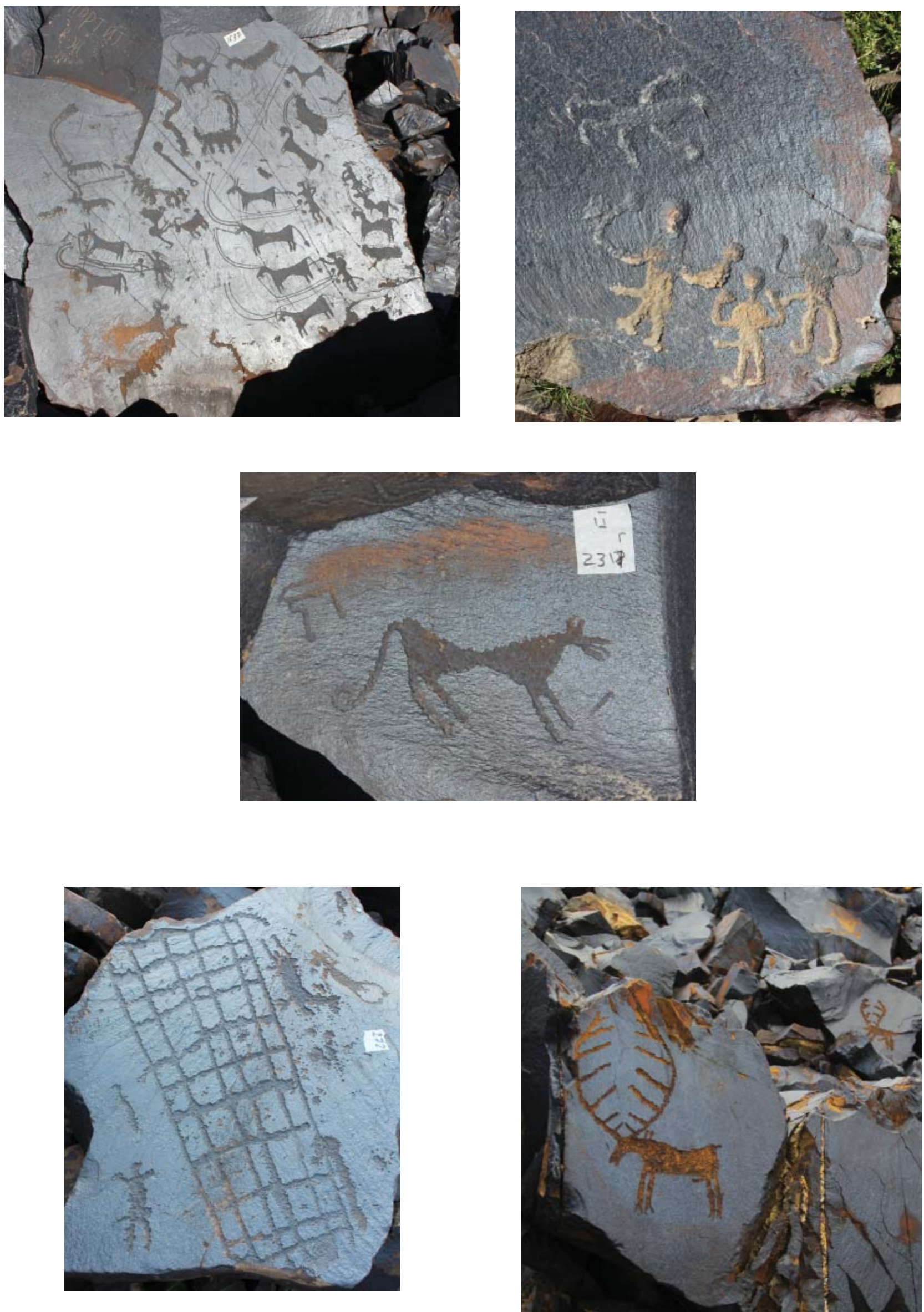

Рис. 5. Петроглифы памятников Саймалы-Таш I и II

Fig. 5. Petroglyphs of the monuments of Saimala-Tash I and II 

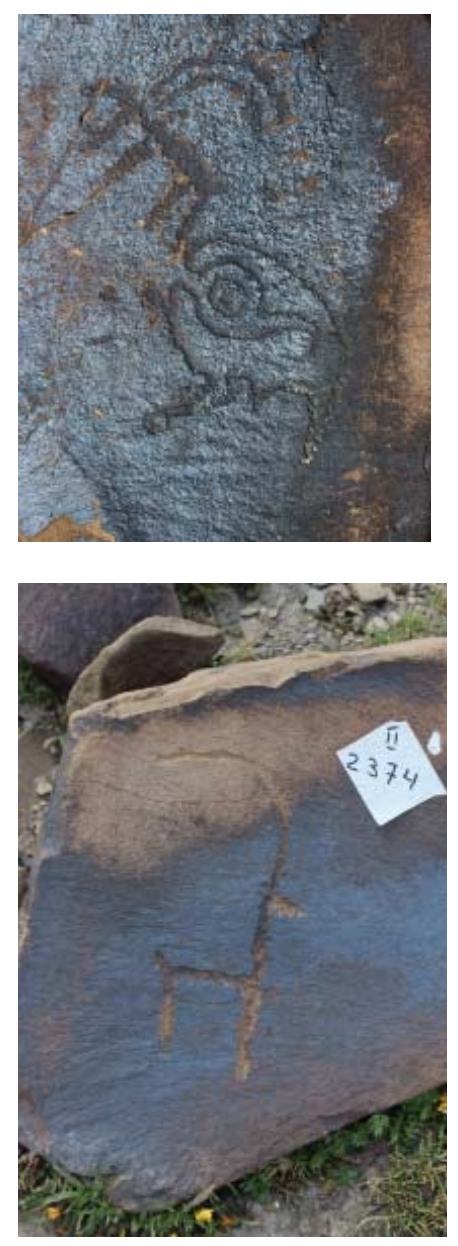
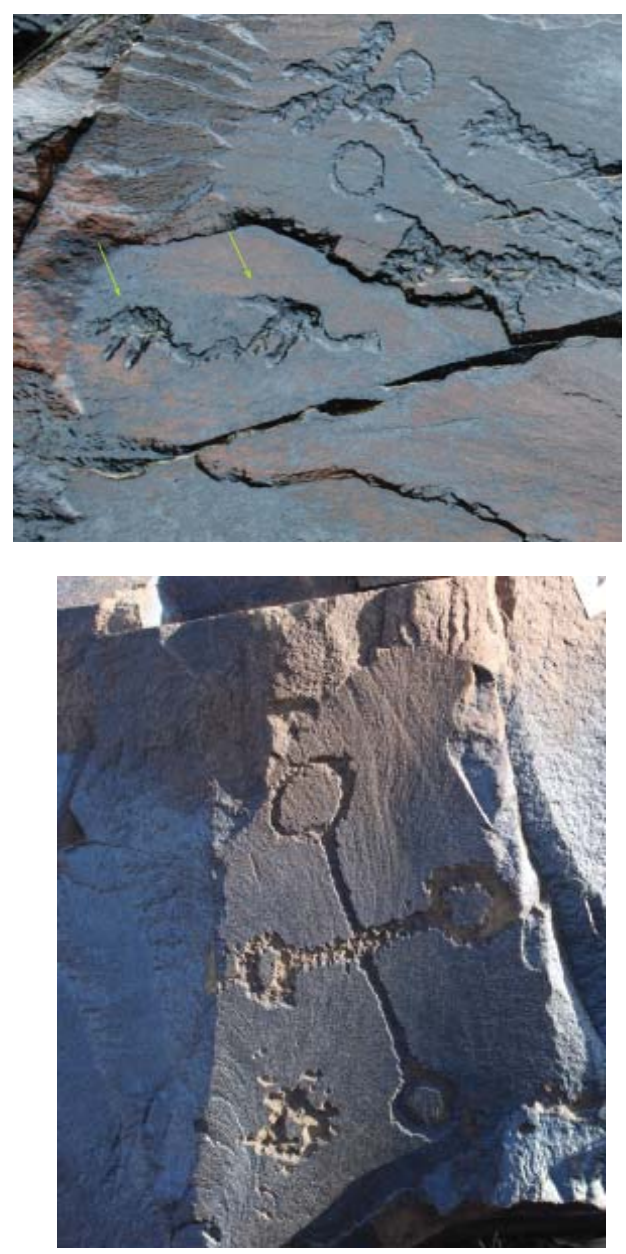
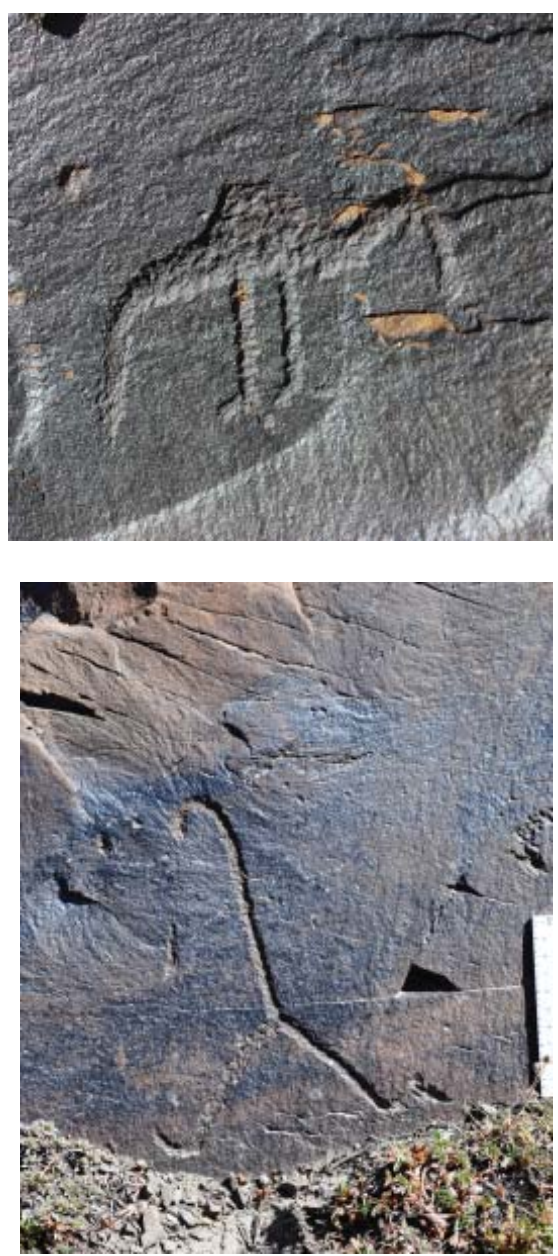

Рис. 6. Изображение птиц и непонятый персонаж. Саймалы-Таш I

Fig. 6. The image of birds and a misunderstood character. Saimaly-Tash I

ми изображениями разного стиля и техники исполнения. Это, несомненно, препятствует тому, чтобы проследить стиль, мотив и принадлежность к определенному периоду. При этом нередко встречаются и палимпсесты.

Мониторинг. На сегодняшний день общее физическое состояние памятника СаймалыТаш, точнее камней с рисунками на их поверхности, можно оценить условно как удовлетворительное. С развитием туризма активно разрабатываются маршруты, демонстрирующие достопримечательности страны, включая археологические объекты. Петроглифы Саймалы-Таша как одного из самых интересных объектов страны, безусловно, находятся в их числе. Его вводят в рекламу туристических агентств, использующих печатные издания и интернет-ресурсы, с целью увеличения числа туристов как внутри страны, так и извне. Но труднодоступное местоположение памятника и краткий летний период ограничивают доступ большого числа посетителей. Поэтому бытует мнение, что такие условия уменьшают риск нанесения с их стороны физического вреда петроглифам. Однако при недавнем осмотре исследователями всего комплекса камней с древними изображениями были обнаружены многочисленные надписи, выбитые нашими современниками с указанием имени и даты своего визита. Подобные надписи появляются все чаще, особенно в последние годы. В результате исторический облик памятника наскального искусства катастрофически быстро изменяется. Реальность показывает, что труднодоступное расположение наскальных изображений и непредсказуемая суровая погода высокогорья не могут защитить памятник от негативного антропогенного воздействия. Невозможно обеспечить сохранение памятника лишь ограничением посещений и контролем над туристами. Поэтому необходимо ставить более широкие задачи по разработке и проведению комплекса мероприятий с целью сохранения и использования данного памятника. 

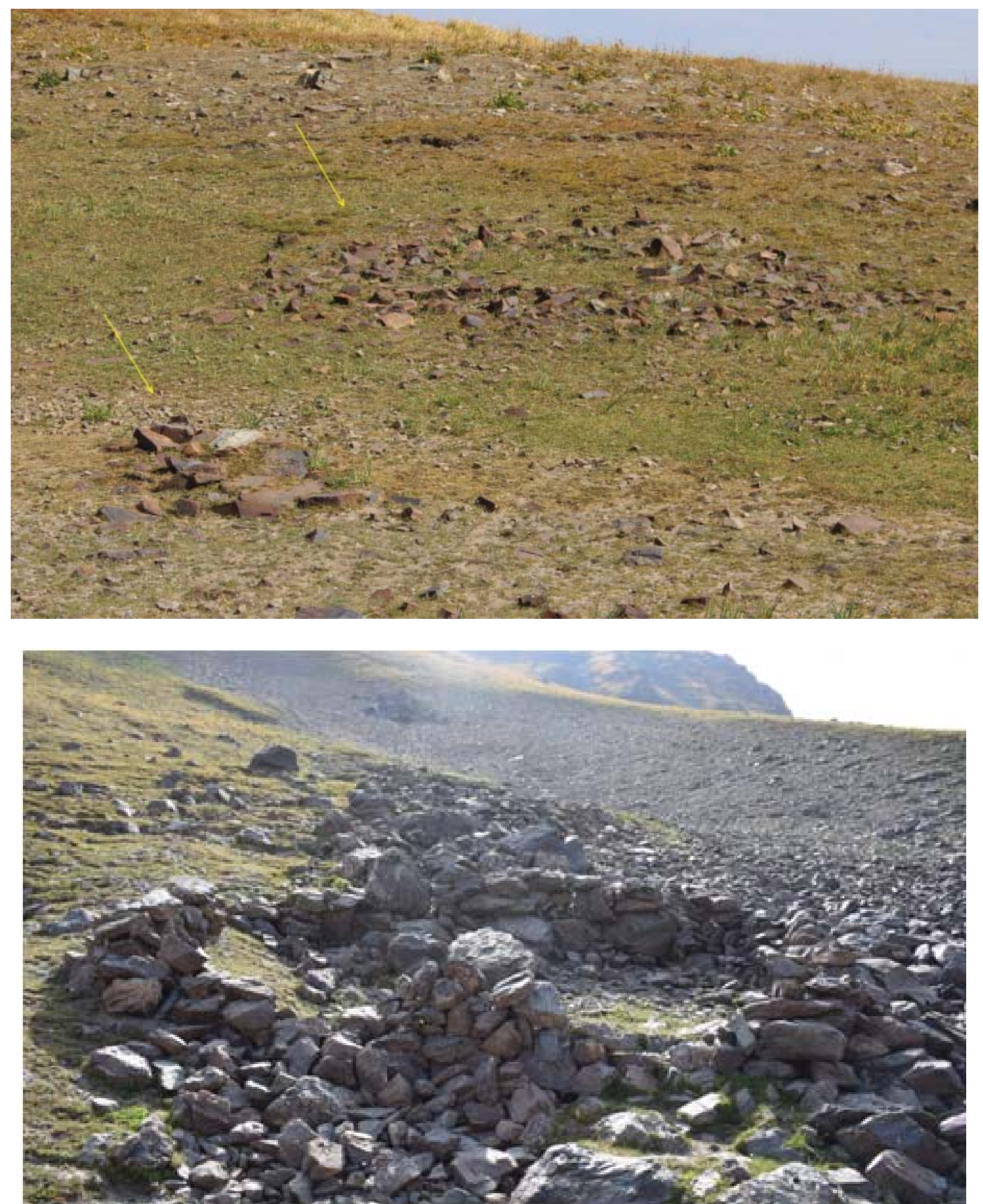

Рис. 7. Курганы на Саймалы-Таш 2 и каменное ограждение (стоянка?) в верховье ущелья Аубек (восточная часть природного парка Саймалуу-Таш) Fig. 7. Mounds on Saimaly-Tash 2 and a stone fence (parking lot?) in the upper reaches of the Aubek Gorge (eastern part of the Saimaluu-Tash Nature Park)

\section{Каждые исследования памятника} Саймалы-Таш дают новые данные и возможности раскрыть еще неизвестные нам события истории и культуры населения, проживавшего в районе этого памятника. Поэтому выявление таких объектов, как поселения, стоянки, погребальные и поминальные сооружения, петроглифы, тамги-знаки и т. п. (рис. 7), в окрестностях Саймалы-Таша будет иметь большое значение. Но в настоящее время не хватает современного комплексного исследования Саймалы-Таша.

Разведывательные работы проводились в соседних просторных ущельях, удобных для пастбища скота и проживания пастухов. В этих местах зафиксировано несколько мест расположения временных стоянок и загонов, сложенных из обломков скальных пород. Как выяснилось, сюда загоняют скот пастухи, выходцы из южных районов (юго-западные 
пределы склонов Ферганского хребта), граничащих с территорией природного парка.

Разведывательные работы в прилегающей территории памятника выявили зону распространения петроглифов между левобережьем р. Саймалы-Таш и восточным склоном безымянного водораздела рек Кок-Арт и Саймалы-Таш. Основное их количество сосредоточено в верхней части безымянной горы (к западу от отрога Саймалы-Таш), где также лежат обвальные обломочные камни с различной степенью загара. Порода камней и цвет их патины (степень загара) идентичны с субстратом основного скопления петроглифов. По происхождению они являются обвалом коренных скальных выходов на восточном склоне горы-водораздела. Здесь также имеются ледниковый цирк и озеро из талых вод, образованное у его входа. Эта часть котловины (восточный склон горы), обозначенная нами западной субзоной СаймалыТаша I, осмотрена до места сужения долины.

Репертуар петроглифов на этих участках также разнообразный, стиль и техника исполнения изображений практически схожи с основными скоплениями наскальных рисунков Саймалы-Таша I и II. Размеры этих рисунков, видимо, зависят от размеров плоскостей камня.

Следующие маршрутные разведки были проведены на восточных, северо-восточных склонах хребта Саймалы-Таш и в верховьях соседнего ручья Конур-Добе. Это снежник Муз-Тор с озерами, расположенными в вершинной зоне водоразделов Саймалы-Таш и Кок-Чолок. В верхней зоне ущелья петроглифы отсутствуют, в нижней части встречались несколько рисунков, выбитых на небольших, рассеянно лежащих обломках камней.

Также был проведен осмотр зон за перевалом (безымянной) долины СаймалыТаш (юго-западные склоны Ферганского хребта - бассейн р. Аубек), верховьев и западных склонов безымянной горы - водораздела рек Кок-Арт и Саймалы-Таш и до перевала Кок-Арт.

Так, в юго-восточной части заповедника по юго-западному склону Ферганского хребта маршрут дошел до верховьев хребта Семиз. На протяжении этого пути встречались камни с рисунками различных видов горных козлов и собак позднего периода. В верховьях хребта Семиз оказалось джайлоо (высокогорное летнее пастбище) с платообразной равниной. Именно здесь находятся сезонные стойбища пастухов, пришедших из Узгенского района (южный регион Кыргызстана). Вопрос, почему именно там, чем привлекала эта местность своих художников? Обвалочные камни с загаром? Удобство или все-таки свою роль играло наличие перевала, по которому гоняли скот в Ферганскую долину с Внутреннего Тянь-Шаня? К примеру, отметим, соседняя долина р. Аубек Восточный (наименование по топокарте) Ферганского хребта используется скотоводами как пастбище. Эта долина доступна с северо-восточной и юго-западной стороны хребта, т. е. со стороны Ферганской долины и Внутреннего Тянь-Шаня. Сюда кочуют скотоводы в основном из Узгенской впадины через перевал Аубек, а через «саймалы-ташский» перевал - пастухи из Сузакского района (соседний район с Узгенским).

Жители из близлежащих регионов считают, что Саймалы-Таш - священная местность, а наскальные рисунки выбиты их предками, и уверены в том, что в урочище особый микроклимат с магической средой.

Озеро, расположенное в центральной части долины, считается священным, местом обитания духов предков и покровителей кайберенов (дикие жвачные животные). Посетители из ближайших районов и пастухи рассказывают, что не всем желающим удается побывать в Саймалы-Таше. По их поверьям, духи этой местности не желают появления недружелюбного посетителя. Поэтому нежеланный человек не сможет попасть в Саймалы-Таш. А причиной тому могут быть различные неожиданные препятствия, или, находясь уже на месте, человек получит телесные травмы.

Наличие этого поверья среди местных жителей свидетельствует о существования зависимости людей от «необъяснимых», сверхъестественных явлений природы, происходящих именно в урочище Саймалуу-Таш. Это демонстрирует особое отношения людей к этой долине, возникшее благодаря петроглифам и моренному озеру. В приписывании озеру священности также играет роль наличие древних рисунков, которые воспринимаются как признак того, что издревле это место 
было священным, особым, что современное поколение также продолжает почитать и поклоняться духам предков и эти петроглифы оставлены неспроста.

Поэтому люди, знакомые с этой местностью, верят в то, что плохие поступки и намерения не нравятся духам предков и покровителям священной местности.

Подобные сведения, связанные с местностью и самим памятником Саймалы-Таш, важны в комплексном исследовании данного объекта. Несомненно, легенды выступают показателем актуальности поддержки живой связи с далеким прошлым, через почитание духов предков и их деяний оживляют исто-

\section{Примечание:}

${ }^{1}$ Цифры приведены из рукописной версии монографии Г. А. Агафоновой и И. К. Кожомбердиева «Петроглифы Саймалы-Таша, Иссык-Куля и Кетмень-Тюбе» (Фрунзе 1978. 175 с.), которая не вышла в свет.

\section{ЛИТЕРАТУРА}

Бернштам А.Н. Наскальные изображения Саймалы-Таш // Избранные труды по археологии и истории кыргызов и Кыргызстана. Т.І. / Отв. ред. О. Караев. Бишкек: Шам, 1996. С. 388-407.

Голендухин Ю.Н. Вопросы классификации и духовный мир древнего земледельца по петроглифам Саймалы-Таша // Первобытное искусство / Отв. ред. Р.С. Васильевский. Новосибирск: Наука, 1971. C. $181-202$.

Джусупакматов Л.Дж. Семантика пиктографии петроглифов Саймалы-Таша. Ош, 2006. 188 с.

Зима Б.М. К вопросу о происхождении наскальных изображений // Труды Киргизского государственного педагогического института. Вып. 2. Фрунзе, 1948. С. 3-21.

Зима Б.M. Некоторые выводы по вопросу изучения наскальных изображений Киргизии // Труды Киргизского государственного педагогического института. Серия историческая. Вып. 2. Фрунзе, 1950. C. 54-74.

Зима Б.М. Из истории изучения наскальных изображений Киргизии // Труды Института истории АН Кирг.ССР. Вып. 4. Фрунзе, 1958. С. 111-124.

Мартынов А.И., Марьяшев А.Н., Абатеков А.К. Наскальные изображения Саймалы-Таша. АлмаАта, 1992. 109 c.

Марьяшев A. Н., Рогожинский A. E. Вопросы периодизации и хронологии петроглифов Казахстана// Скифо-сибирский мир: искусство и идеология / Отв. ред. А. И. Мартынов, В. И. Молодин. Новосибирск: Наука, 1987. С. 55-59.

Подольский Н.Л. О классификации наскальных изображений Саймалы-Таш Ферганского хребта // Доклады Восточной комиссии Географического общества. Вып. 3. Л., 1966. С. 24-41.

Помаскина Г.А. Исследование наскальных изображений Тянь-Шаня // Археологические открытия 1973 года / Отв. ред. Б.А. Рыбаков М.: Наука, 1974. С. 531-533.

Помаскина Г.А. Наскальная галерея Саймалы-Таш (к истории исследования) // Страницы истории и материальной культуры Киргизстана (досоветский период) / Ред. Б. Д. Джамгерчинов и др. Фрунзе: Илим, 1975а. С. 181-185.

Помаскина Г.А. Некоторые результаты статистического исследования изображений Саймалы-Таша // Известия АН Киргиской ССР. 1975. № 3. С. 108-113.

Помаскина Г.А. Когда боги были на земле... (Наскальная галерея Саймалы-Таша). Фрунзе: Кыргызстан. $1976.36 \mathrm{c}$.

Пославский И.Т. Из поездки в Саймалы-Таш // Протоколы Туркестанского кружка любителей археологии (11 декабря 1902 года 11 декабря 1903 года), год VIII. Ташкент, 1903. C. 75-83.

Рогожинский A.E. О современных задачах археологии наскального искусства Казахстана и Средней Азии // Археология, этнография и антропология Евразии. 2008. № 4(36). С. 83-94. 
Сулайманова А.Т., Жолдошов Ч.М., Дуйшаналиева А.Т. Археологический ландшафт Саймалы-Таш. Бишкек: Улуу Тоолор, 2016. 304 с.

Ташбаева К.И. Памятники Кыргызстана // Памятники наскального искусства Центральной Азии. Общественное участие, менеджмент, консервация, документация / Отв. ред. А.Е. Рогожинский. Алматы, 2004. С. 93-106.

Ташбаева К.И. К проблеме датировки битреугольного стиля в наскальном искусстве Центральной Азии // Древности Восточной Европы, Центральной Азии и Южной Сибири в контексте связей и взаимодействий в евразийском культурном пространстве (новые данные и концепции): Материалы Международной конференции, 18-22 ноября 2019 г., Санкт-Петербург. Т. ІІ. Связи, контакты и взаимодействия древних культур Северной Евразии и цивилизаций Востока в эпоху палеометалла (IV-I тыс. до н.э.). К 80-летию со дня рождения выдающегося археолога В.С. Бочкарева / Отв. ред. А.В. Поляков, Е.С. Ткач. СПб.: ИИМК РАН, Невская Типография, 2019. С. 213-214.

Хлудов Н.Г. Перевал Саймалы-Таш, на котором найдены камни с надписями // Протоколы Туркестанского кружка любителей археологии. (11 декабря 1901 года - 1 декабря 1902 года). Год VII. Ташкент, 1902. C. 40-43

Шер Я.А. К интерпретации сюжетов некоторых петроглифов Саймалы-Таша // Культура востока. Древность и раннее средневековье / ред. В.Г. Луконин. Л.: Аврора, 1978. С. 163-171.

Шер Я.А., Голендухин Ю.Н. Колесницы Саймалы-Таша // По следам памятников истории и культуры Киргизстана / ред. В. М. Массон, В. М. Плоских.Фрунзе: Илим, 1982. С. 18-25.

\section{Информация об авторе:}

Сулайманова Айдай Турдумаматовна, научный сотрудник, Институт истории, археологии и этнологии им. Б. Джамгерчинова Национальной академии наук Кыргызской Республики (г. Бишкек, Кыргызская Республика); aidaisu@yandex.com

\section{REFERENCES}

Bernshtam, A. N. 1996. In Karaev, O. (ed.). Izbrannye trudy po arkheologii i istorii kyrgyzov i Kyrgyzstana (Selected works on archaeology and history of the Kyrgyz and Kyrgyzstan). Bishkek: "Sham" Publ., 388-407 (in Russian).

Golendukhin, Yu. N. 1971. In Vasilevsky, R. S. (ed.). Pervobytnoe iskusstvo (Primeval art). Novosibirsk: "Nauka" Publ., 181-202 (in Russian).

Dzhusupakmatov, L. Dzh. 2006. Semantika piktografii petroglifov Saimaly-Tasha (Semantics of pictography of petroglyphs of Saimaly-Tash). Osh (in Russian).

Zima, B. M. 1948. In Trudy Kirgizskogo gosudarstvennogo pedagogicheskogo instituta (Proceedings of the Kyrgyz State Pedagogical Institute) 2, 3-21 (in Russian).

Zima, B. M. 1950. In Trudy Kirgizskogo gosudarstvennogo pedagogicheskogo instituta (Proceedings of the Kyrgyz State Pedagogical Institute) 2, 54-124 (in Russian).

Zima, B. M. 1958. In Trudy Kirgizskogo gosudarstvennogo pedagogicheskogo institute (Proceedings of the Kyrgyz State Pedagogical Institute) 4, 11-124 (in Russian).

Martynov, A. I., Mar'yashev, A. N., Abatekov, A. K. 1992. Naskal'nye izobrazheniia Sajmaly-Tasha (Rock carvings of Saimaly-Tash). Alma-Ata (in Russian).

Mar'yashev, A. N., Rogozhinsky, A. E. 1987. In Martynov, A. I., Molodin, V. I. (eds.).Skifo-sibirskii mir: iskusstvo i ideologiia (The Scythian-Siberian World: art and ideology). Novosibirsk: "Nauka" Publ., 55-59 (in Russian).

Podol'sky, N. L. 1966. In Doklady Vostochnoi komissii Geograficheskogo obshchestva (Reports of the Eastern Commission of the Geographical Society) 3, 24-41 (in Russian).

Pomaskina, G.A. 1974. In Rybakov, B. A. (ed.). Arkheologicheskie otkrytiia 1973 goda (Archaeological Discoveries of 1973). Moscow: "Nauka" Publ., 531-533 (in Russian).

Pomaskina, G. A. 1975. In Dzhamgerchinov, B. D. et al. (eds.). Stranitsy istorii i material'noi kul'tury Kirgizstana (dosovetskii period) (Pages of history and material culture of Kyrgyzstan (pre-Soviet period)). Frunze: "Ilim" Publ., 181-185 (in Russian).

Pomaskina, G. A. 1975. In Izvestiia Akademii nauk Kirgizskoi SSR (Bulletin of the Academy of Sciences of the Kyrgyz SSR) 3, 108-113 (in Russian).

Pomaskina, G. A. 1976. Kogda bogi byli na zemle... (Naskal'naia galereia Saimaly-Tasha) (When the gods were on earth... (Saimaly-Tash Rock Gallery)). Frunze: "Kyrgyzstan” Publ. (in Russain). 
Poslavsky, I. T. 1903. In Protokoly Turkestanskogo kruzhka liubitelei arkheologii (11 dekabrja 1902 goda 11 dekabrja 1903 goda), god VIII (Protocols of the Turkestan Circle of Archeology Lovers (December 11, 1902 December 11, 1903), year VIII). Tashkent, 75-83 (in Russian).

Rogozhinsky, A. E. 2008. In Arkheologiia, etnografiia i antropologiia Evrazii (Archaeology, Ethnology \& Anthropology of Eurasia) 36 (4), 83-94 (in Russian).

Sulaimanova, A. T., Zholdoshov, Ch. M., Duishanalieva, A. T. 2016. Arkheologicheskii landshaft SamalyTash (Archaeological landscape of Saimaly-Tash). Bishkek: "Uluu Toolor" Publ. (in Russian).

Tashbaeva, k. I. 2004. In Rogozhsky, A. E. (ed.). Pamiatniki naskal'nogo iskusstva Tsentral'noi Azii. Obshchestvennoe uchastie, menedzhment, konservatsiia, dokumentatsiia) (Rock art monuments of Central Asia. Public participation, management, conservation, documentation). Almaty, 93-106 (in Russian).

Tashbaeva, K. I. 2019. In Polyakov, A. V., Tkach, E. S. (eds.) Drevnosti Vostochnoi Evropy, Tsentral'noi Azii i Iuzhnoi Sibiri v kontekste sviazei i vzaimodeistvii v evraziiskom kul'turnom prostranstve (novye dannye $i$ kontseptsii (Antiquities of Eastern Europe, Central Asia and Southern Siberia in the Context of Relations and Interactions in the Eurasian Cultural Space (New Information and Concepts) 2. Saint Petersburg: Institute for the History of Material Culture, Russian Academy of Sciences, "Nevskaia Tipografiia" Publ., 213-214 (in Russian).

Sher, Ya. A., Golendukhin, Yu. N. 1982. In Masson, V. M., Ploskikh, V. M. (eds.) (In the footsteps of historical and cultural monuments of Kyrgyzstan). Frunze: "Ilim" Publ., 18-25 (in Russian).

Khludov,v N. G. 1902. In Protokoly Turkestanskogo kruzhka liubitelei arkheologii (11 dekabria 1901 goda - 1 dekabria 1902 goda), god VII (Protocols of the Turkestan Circle of Archeology lovers (December 11, 1901 - December 1, 1902), year VII). Tashkent, 40-43 (in Russian).

Sher, Ya. A. 1978. In Lukonin, V. G. (ed.). Kul'tura vostoka. Drevnost' i rannee srednevekov'e (Culture of the East. Antiquity and the Early Middle Ages). Leningrad: "Avrora" Publ., 163-171 (in Russian).

\section{About the Author:}

Sulaimanova Aidai T. B. Jamgerchinov Institute of History, Archeology and Ethnology of the National Academy of Sciences of the Kyrgyz Republic. 265a Chuy Avenue, Bishkek, 720071, Kyrgyz Republic; aidaisu@yandex.com 